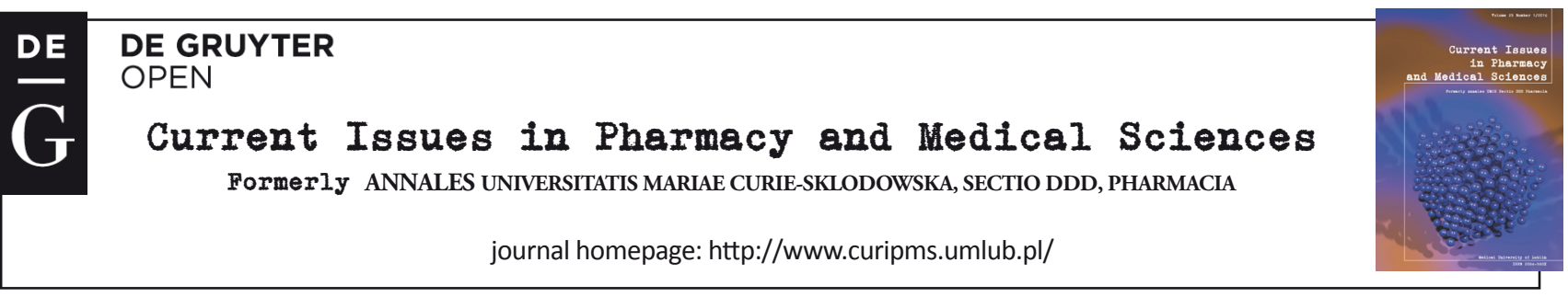

\title{
Oxidative metabolism of neutrophils in patients with community-acquired pneumonia
}

\author{
Lyudmila Andreevna Demidchik, Valentina Vitalyevna Lee, \\ Larissa Yevgenyevna Muravlyova*, Vilen Borisovich Molotov-Luchanskiy, \\ Ryszhan Yemelyevna Bakirova, Dmitriy Anatolyevich Klyuyev, \\ Yevgeniya Alexandrovna Kolesnikova
}

Karaganda State Medical University, Gogol 40, 100008 Karaganda, Republic of Kazakhstan

\begin{tabular}{|c|c|}
\hline ARTICLE INFO & ABSTRACT \\
\hline $\begin{array}{l}\text { Received } 16 \text { January } 2016 \\
\text { Accepted } 01 \text { March } 2016\end{array}$ & $\begin{array}{l}\text { At the present time, available views show our limited knowledge of the peculiarities of } \\
\text { the functional status of neutrophils and their metabolism in patients with community- }\end{array}$ \\
\hline $\begin{array}{l}\text { Keywords: } \\
\text { neutrophils, } \\
\text { oxidative modified proteins, } \\
\text { community-acquired } \\
\text { pneumonia. }\end{array}$ & $\begin{array}{l}\text { acquired pneumonia (CAP). The studying of changes of metabolic status of neutrophils } \\
\text { can broaden our views about pneumonia pathogenesis and define datum points of } \\
\text { therapeutic effect. } \\
\text { Purpose of our research: to define oxidative stress activity and the level of oxidative } \\
\text { modification of proteins of neutrophils in CAP patients. } \\
\text { Materials and methods: neutrophils obtained from } 23 \text { patients with community- } \\
\text { acquired pneumonia. Control group consisting of } 19 \text { healthy volunteers. The reactive } \\
\text { carbonyl derivatives of proteins and advanced oxidation protein products were defined } \\
\text { so as to assess the oxidative damage of proteins. The malondialdehyde and nitrite ions } \\
\text { were assessed as being indicators of the oxidative stress. The neutrophils of CAP patients } \\
\text { with moderate severity were characterized by a tendency of evidencing decreasing } \\
\text { content of advanced oxidation protein products, along with the statistically important } \\
\text { enhanced levels of carbonyl derivatives and nitrite ions, while their malondialdehyde } \\
\text { status practically leveled off with the control and had only an insignificant trend towards } \\
\text { growth. We have demonstrated the accumulation of carbonyl derivatives and nitrite ions } \\
\text { in the peripheral neutrophils of CAP patients. These results give evidence of an oxidative } \\
\text { misbalance in the cells which contributes to the aggravation of the disease. }\end{array}$ \\
\hline
\end{tabular}

\section{INTRODUCTION}

A study of the functional and metabolic changes in the status of neutrophils is one of the more important areas of researches in as far as it determines in many aspects, the development and outcome of acute pneumonia [13].

The activation of neutrophils, the generation of active oxygen forms and the secretion of granules with antimicrobial proteins play a large role in the elimination of the pathogen, while elongation of granulocyte activity contributes towards lung tissue affection and unfavorable outcome when afflicted with pneumonia [1]. Being obligate participants in inflammation, neutrophils have dual purpose: on the one hand, it is protective, on the other - they are potential mediators of tissue injury. Segel et al. suggest several of

\footnotetext{
^ Corresponding author

e-mail: lem2403@mail.ru
}

their damaging effects: adhesion of activated neutrophils on the endothelium, production of active oxygen forms, protease secretion and creation of conditions for local vascular and tissue lesion [8]. Zimmermann et al. [14] show that the neutrophils isolated from the blood of communityacquired pneumonia (CAP) patients had reduced ability both for spontaneous and stimulated exocytosis. This had been estimated by the secretion of lactoferrin. At the same time, a sharp rise in the neutrophils' faculty to produce active oxygen forms was noticed. Neutrophils obtained from lung tissue produced more myeloperoxidase and lactoferrin than did ones from the same patients' blood system. However, the stimulation of exocytosis did not depend on the primary localization of cells: pneumonia is accompanied by exocytosis damage of blood neutrophils to a greater extent than that within cells obtained from the lung population. In the 
authors' opinion, this situation is due to the heavy infectious process, which shortens the maturation time of the cells.

By studying the metabolic status of neutrophils, a reliable amplification of superoxidants production was established in reply to their stimulation, in comparison with a control level [9]. In our work, a misbalance in the glutathione redox system of neutrophils in CAP patients was revealed: herein, we saw a lowering maintenance of reduced glutathione, thiol groups and glutathione peroxidase activity, with concurrent increasing of oxidized and protein-associated forms of glutathione. The neutrophils of CAP patients were also seen to have rising maintenance of oxidized carbonyl proteins. This phenomenon can be explained by way of the decreasing of the thiol disulfide system's redox potential [12]. Available views show our limited knowledge of the peculiarities of the functional status of neutrophils and their metabolism in CAP patients. Hence, further investigation of oxidized proteins and reactive aldehydes should be accentuated, as they possibly can be triggers of fatal changes in the metabolic status of immunocompetent blood cells, thus, contributing towards irreversible aggravation of pneumonia, its resistance to treatment and development of respiratory distress syndromes. In this connection, the studying of neutrophils metabolic status changes in CAP patients can broaden views about severe pneumonia pathogenesis.

\section{AIM}

The main purpose of our research was to define oxidative stress activity and the level of oxidative modification proteins of neutrophils in CAP patients.

\section{MATERIAL AND METHODS}

There were 2 groups of subjects. The first (basic) group consisted of 23 CAP patients with moderate lobar pneumonia or two-three affected segments and with respiratory insufficiency of II degree. The mean age of basic group participants was $51.6 \pm 1.6$ years old, by gender: $18(78.3 \%)$ male and 5 female $(21.7 \%)$. The percent of excessive tobacco users reached $37.5 \%$, the index of smoking person $-18.3 \pm 3.26$ pack-years. Including criteria were: moderate pneumonia, patient age not less than 18 years, informed consent. Excluding criteria were: mild and severe pneumonia, comorbidities in the stage of exacerbation, including chronic obstructive pulmonary disease (COPD), pulmonary tuberculosis, heart failure etc. Verification of the diagnosis was carried out and based on standard criteria: X-ray indications of lung consolidation, increase of the body temperature, cough and sputum, data of physical exam, respiratory insufficiency and acute inflammatory changes in the blood count. Average duration of the pneumonia in group was 10.1 \pm 6.5 days. The control (second) group consisted of 19 healthy volunteers of similar age, who were nonsmokers and who were without signs of any inflammation.

Ethics. The medical ethics committee of the Medical University (Karaganda) approved the study. All patients and healthy subjects received full information on probable inconveniences and complications regarding blood sampling before giving their consent to participate.
Blood sampling was made in morning hours. Blood was collected from the brachial vein $(6 \mathrm{ml} / \mathrm{sample})$, and was drawn into Vacutainer tubes containing heparin. The protocol of Fedorova and Levin was used to obtain neutrophils and to prepare cell-lysate [3]. The purity and viability of the obtained neutrophils were assessed by trypan blue dye exclusion. Samples of $>85 \%$ neutrophils with $>90 \%$ viability were gathered. Cell count was standardized up to 1 million in $1 \mathrm{ml}$ of medium. The count of neutrophils was enabled through using a Mindray BC-3200 Hematology Analyzer. Suspensions of neutrophils in the concentration of $10^{6}$ cells/ $\mathrm{ml}$ were lysed by freeze-thawing.

The amount of protein reactive carbonyl derivatives (PRCD) and advanced oxidation protein products (AOPP) was defined so as to assess the oxidative damage of proteins in the neutrophil lysate. Moreover, the levels of malondialdehyde (MDA) and nitrite (one of the stable product of NO oxidation pathway) were estimated, as such were considered to be indicators of the oxidative stress intensity. PRCD concentration was detected through application of dinitrophenylhydrazine, following the protocol of Levine et al. [5]. PRCD concentration was calculated using the extinction coefficient at $370 \mathrm{~nm}=22.000 \mathrm{~mol}^{-1} \mathrm{~cm}^{-1}$, while AOPP content in neutrophil lysate was determined using the method of Witko-Sarsat et al. [10]. Of note, malondialdehyde assay after reaction with thiobarbituric acid is the most commonly employed method for assessing lipid peroxidation in biological samples. The concentration of thiobarbituric acid reactive substances was calculated by way of utilizing the extinction coefficient of $1.56 \times 10^{5} \mathrm{M}^{-1} \mathrm{~cm}^{-1}$ $[4,6]$. Thiobarbituric reactive substances concentration was expressed in terms of $\mu \mathrm{mol}$ malondialdehyde per $10^{6}$.

Finally, spectrophotometric detection of nitrite concentration was enabled through employing the Griess reaction. An extinction coefficient of $38.000 \mathrm{M}^{-1} \mathrm{~cm}^{-1}$ was employed for the calculation of nitrite level [7].

Statistical data processing was made with Shapiro-Wilk criterion to test normality in distribution, t-testing was done to assess any distinction between groups (such distinctions were considered reliable if $\mathrm{p}$-value $<0,05$ ), while correlation analysis was undertaken to reveal any relation between the studied parameters.

\section{RESULTS}

While determining the level of oxidative modified proteins within the neutrophils, a statistically significant increase in the content of PRCD in CAP patients, in comparison to control group values, was found $(p<0,0001)$ (Table 1).

Table 1. Oxidative stress related-parameters in the neutrophils of CAP patients

\begin{tabular}{|l|c|c|}
\hline $\begin{array}{c}\text { Oxidative stress related- } \\
\text { parameters }\end{array}$ & $\begin{array}{c}\text { CAP patients with moderate } \\
\text { severity }(\mathrm{n}=23)\end{array}$ & $\begin{array}{c}\text { Control group } \\
(\mathrm{n}=19)\end{array}$ \\
\hline PRCD $\left(\mathrm{nmol} / 10^{6}\right)$ & $0.451 \pm 0.260 *$ & $0.204 \pm 0.082$ \\
\hline AOPP $\left(\mu \mathrm{mol} / 10^{6}\right)$ & $0.037 \pm 0.015$ & $0.048 \pm 0.020$ \\
\hline Nitrite ions $(\mu \mathrm{mol} / \mathrm{ml})$ & $1.997 \pm 0.866 \#$ & $1.324 \pm 0.538$ \\
\hline MDA $\left(\mu \mathrm{mol} / 10^{6}\right)$ & $0.783 \pm 0.283$ & $0.692 \pm 0.202$ \\
\hline * - statistically significant difference compared to control, $\mathrm{p}<0.0001$ \\
\# - statistically significant difference compared to control, $\mathrm{p}=0.02$
\end{tabular}


Furthermore, there was a trend of decreasing in regard to the AOPP level in the neutrophils of all CAP patients, when compared to the control group. However, in the neutrophils of $87 \%$ of all CAP patients, the MDA concentration did not differ from control values; in $13 \%$ of all patients, the level of MDA exceeded control group values.

Statistically, a considerable increase in the level of nitrite ions in the neutrophils of CAP patients, in comparison to control group values was detected $(p=0.02)$. It should be noticed that in the CAP patient group, no values were lower than those in the control group.

Finally, in studying correlations in CAP patients, a reverse link between MDA and PRCD level was revealed $(\mathrm{r}=-0.7, \mathrm{p}<0.05)$, as was also shown between AOPP and $\operatorname{PRCD}(\mathrm{r}=-0.7, \mathrm{p}<0.05)$. The control group was characterized as demonstrating a reverse link between NO and PRCD $(\mathrm{r}=-0.6, \mathrm{p}<0.05)$.

\section{DISCUSSION}

According to results of our researches, the neutrophils of CAP patients with moderate severity are characterized by displaying the tendency of a decreasing AOPP content along side a statistically significant considerable increasing of the levels of PRCD and nitrite ions. In addition, their MDA content is practically leveled off with control and had only an insignificant trend to growth.

Evidence from diverse sources suggests that nitrite ions could be an active precursor to reactive nitrogen species within cells including neutrophils [2]. In neutrophils nitrite ions could inhibit tyrosyl group chlorination by way of myeloperoxidase-generated $\mathrm{HOCl}$ or could directly react with $\mathrm{HOCl}$ leading to the formation of nitryl chloride and hydroxide ions. Of note, nitryl chloride is less reactive than $\mathrm{HOCl}$ toward the target proteins [2].

In our opinion, based on the obtained results, the aforementioned could explain the AOPP decreasing and PRCD boosting in the neutrophils of CAP patients. Such an effect is confirmed by way of the statistically significant reverse link between PRCD and AOPP levels in the neutrophils of CAP patients $(\mathrm{r}=-0.7, \mathrm{p}<0.05)$.

What is more, the elevation of PRCD may be connected with the increasing of the intracellular reactive oxygen species generated by different cytokines, which synthesis is enlarged in conditions of inflammation [11]. Furthermore, the presence of the reverse link between PRCD and MDA $(\mathrm{r}=-0.7, \mathrm{p}<0.05)$ levels in the obtained neutrophils has given us the chance to propose that the formation of abnormal protein adducts with MDA comes about when individuals are afflicted with moderate pneumonia.
To sum up, accumulation of the reactive protein carbonyl derivatives and nitrite ions in neutrophils gives evidence of an oxidative misbalance in the cells. This situation comes about when afflicted with pneumonia of moderate severity and is undoubtedly due to its effects on lung tissue. Moreover, it contributes towards the aggravation of the disease.

There were two limitations of our research: the investigation of neutrophils in CAP patients with only moderate severity and the absence of the influence of treatment on neutrophils oxidative stress indicators. The effect of these limitations will be included in the field of our scientific interests. To conclude we feel that it will very useful to estimate the effectiveness of CAP treatment and the possible diagnostics of CAP severity by way of oxidative stress indicators.

\section{REFERENCES}

1. Bordon J. et al.: Understanding the roles of cytokines and neutrophil activity and neutrophil apoptosis in the protective versus deleterious inflammatory response in pneumonia. Int. J. Infect. Dis., 17, 2, 2013.

2. Cape J. L., Hurst J. K.: The role of nitrite ion in phagocyte functionperspectives and puzzles. Arch. Biochem. Biophys., 484, 2, 2009.

3. Fedorova M.Z.. Levin V.N.: The method of complex study of geometry. surface area. the reserve capacity of the membrane and maintain the body's white blood cells. Clin. Medicine., 8, 2000, (Article in Russian)

4. Goncharenko M.S., Latinova A.M.: Method of assessment of peroxide oxidation of lipids. Lab. case., 1, 1985, (Article in Russian)

5. Levine R.L. et al.: Determination of carbonyl content in oxidative modified proteins. Method. Enzymol., 186, 1990.

6. Premanand R., Kumar S., Mohan A.: Study of thiobarbituric reactive substances and total reduced glutathione as indices of oxidative stress in chronic smokers with and without chronic obstructive pulmonary disease. Indian J. Chest Dis. Allied Sci., 49, 2007.

7. Ridnour L. A. et al.: A Spectrophotometric method for the direct detection and quantitation of nitric oxide. nitrite. and nitrate in cell culture media. Analytical Biochemistry, 281, 2000.

8. Segel G. B. et al.: The paradox of the neutrophil's role in tissue injury. Journal of Leukocyte Biology, 89, 3, 2011.

9. Tomczykowska M. et al.: Oxidative metabolism of neutrophils in patients with initial "outside-hospital” pneumonia. Ann. Univ. Mariae Curie Sklodowska Med., 58, 1, 2003.

10. Witko-Sarsat V. et al.: Advanced oxidation protein products as a novel marker of oxidative stress in uremia. Kidney Int., 49. 1996.

11. Yang D. et al.: Pro-inflammatory cytokines increase reactive oxygen species through mitochondria and NADPH oxidase in cultured RPE cells. Exp. Eye Res., 85, 4, 2007.

12. Zhavoronok T.V. et al.: Influence of oxidative stress on redox-state and peripheral blood heterophilic leukocytes apoptotic program realization. European journal of natural history, 6, 2007.

13. Zhou X.et al.: Neutrophils in acute lung injury. Front Biosci. 17, 2012.

14. Zimmermann B. et al.: Impaired neutrophil exocytosis in patients with severe pneumonia. Intensive Care Med., 25, 1, 1999. 